\title{
Greenhouse Energy Consumption for Tomato Production in the Iberian Peninsula Countries
}

\author{
F.J. Baptista ${ }^{1}$, A.T. Silva ${ }^{2}$, L.M. Navas ${ }^{3}$, A.C. Guimarães ${ }^{3}$ and J.F. Meneses ${ }^{4}$ \\ ${ }^{1}$ Universidade de Évora/ICAAM, Dept. de Engenharia Rural, Núcleo da Mitra, Évora, \\ Portugal \\ ${ }^{2}$ Universidade de Évora, Dept. de Engenharia Rural, Núcleo da Mitra, Évora, Portugal \\ ${ }^{3}$ Universidad de Valladolid, Dept. de Ingeniería Agrícola y Forestal, Palencia, Spain \\ ${ }^{4}$ Instituto Superior de Agronomia, Universidade Técnica de Lisboa, Centro de Estudos de \\ Engenharia Rural, Lisboa, Portugal
}

Keywords: greenhouse, tomatoes, energy consumption

\begin{abstract}
Greenhouse climate models are a powerful tool which allows the simulation of inside environmental conditions as a function of external conditions, construction and environmental control equipments characteristics. They also permit to evaluate the energy consumption necessary to obtain the predefined conditions. A theoretical study of the greenhouse energy requirements for all year round tomato production in Portugal and Spain is presented. A Greenhouse Climate Simulator (GCS) was used to analyse the energetic behaviour in different regions. GCS uses mensal mean weather data of several years of solar radiation, temperature, wind speed and relative humidity. A climate generator computes the mean hourly climatic data of a typical day for each month and location. As inputs GCS requires data related with the greenhouse characteristics, environmental control equipment and the crop. For the energy balance a static complex model is used which is based on the physics of heat and mass transfer. The results show the energy consumption due to the heating system in each of the studied locations, as well the heat dissipated by the cooling system along a characteristic year, for year round production in plastic greenhouses. This is used to estimate energy consumption indicators which allow generating predictive maps. It is an interesting tool which may contribute to the grower's decision making and to the reduction of energy consumption, helping to lower production costs and environmental impacts.
\end{abstract}

\section{INTRODUCTION}

Tomato is considered the most important greenhouse crop. The majority of fresh tomatoes marketed in the European Union are produced as protected crops. Greenhouse areas in Mediterranean regions reached 144,000 ha in 1999, with tomato being the most commonly grown vegetable (Castilla, 2002). In 2005, the greenhouse area for vegetable and flower production has reached 53,800 ha in Spain and 2,550 ha in Portugal (Meneses and Castilla, 2009). For tomato greenhouse crops, in order to obtain high yields and good quality, air temperatures should be kept in the range of $20-26^{\circ} \mathrm{C}$ during the day and $15^{\circ} \mathrm{C}$ or above during the night. Temperatures below $14^{\circ} \mathrm{C}$ at night affect fruit set (Atherton and Rudich, 1994).

In most production regions, outside climate conditions are not adequate all over the year to obtain the mentioned conditions inside the greenhouses. In this case it is necessary to use some environmental control techniques, such as heating, ventilation, shading, and cooling to reach the appropriate temperatures. The use of these techniques implies energy consumption, increasing production costs and contributing to $\mathrm{CO}_{2}$ emissions. In Portugal, heating costs could vary between $2.5 € \mathrm{~m}^{-2}$ to more than $15 € \mathrm{~m}^{-2}$ depending on the heating system and on the temperature difference between inside and outside (Meneses and Baptista, 2009).

The climate of the place is one of the main factors influencing the production costs mainly due to the energy requirements to obtain environmental conditions adequate to a specific crop production. FAO (2002) presents the heating power for greenhouse crops as 